\title{
Rainfall Prediction Using Fuzzy Time Series
}

\section{Prediksi Curah Hujan Menggunakan Fuzzy Time Series}

\author{
Adhi Susano \\ Universitas Indraprasta PGRI \\ Jl. Nangka No 58 C, DKI Jakarta \\ adhi.susano@gmail.com \\ Wulan Anggraeni \\ Universitas Indraprasta PGRI \\ Jl. Nangka No 58 C, DKI Jakarta \\ wulan41183@gmail.com
}

\begin{abstract}
$\overline{\text { Abstract }}$
Flood is one of the problems faced by DKI Jakarta Province. To be able to reduce losses caused by flooding is to predict rainfall. The type of research is quantitative research using rainfall prediction method using Fuzzy Time Series (FTS) which was developed by Stevenson \& Porter (2009). The data used is rainfall data at Kemayoran Station in the period January 2018 to December 2020. The prediction accuracy results state that the FTS method has poor accuracy so that improvements are needed in the formation of interval intervals.
\end{abstract}

Keywords: rainfall, prediction, fuzzy time series

Abstrak

Banjir merupakan salah satu permasalahan yang dihadapi oleh Provinsi DKI Jakarta. Untuk dapat mengurangi kerugian yang disebabkan banjir adalah melakukan prediksi curah hujan. Jenis penelitian adalah penelitian kuantitatif dengan menggunakan metode prediksi curah hujan menggunakan Fuzzy Time Series (FTS) yang dikembangkan oleh Stevenson \& Porter (2009). Data yang dipergunakan adalah data curah hujan di Stasiun Kemayoran pada periode Januari 2018 s.d Desember 2020. Hasil Akurasi prediksi menyatakan metode FTS memiliki akurasi yang buruk sehingga diperlukan perbaikan pada pembentukan selang interval.

Kata kunci: curah hujan, prediksi, fuzzy time series

\section{PENDAHULUAN}

Banjir menjadi salah satu permasalahan di DKI Jakarta yang tak kunjung selesai (Eldi, 2020), disebabkan oleh intensitas curah hujan tinggi sehingga kapasitas sungai tidak mampu menampung dan meluap ke daerah sekitarnya (Nugroho, 2002). Musibah banjir besar terjadi pada tahun 2013 yang menyebabkan kerugian mencapai Rp. 20 Triliun (Syaifullah, 2013). Upaya untuk menekan kerugian akibat banjir perlu dilakukan dikarenakan banjir terus berulang tiap tahunnya. Salah satu yang dapat dilakukan adalah dengan memahami fenomena curah hujan dan dapat memprediksinya dengan baik agar dapat terhindar dari bencana yang disebabkan banjir Sumi et al. (2012).

Penelitian terkait prediksi curah hujan telah dilakukan oleh peneliti sebelumnya. Desmonda \& Irwansyah (2018) melakukan penelitian yaitu memprediksi curah hujan di Provinsi Kalimantan Barat menggunakan metode Fuzzy Time Series (FTS) dengan hasil yang diperoleh adalah peramalan memiliki tingkat akurasi sebesar 99,849 \%. Rahmawati et al., (2021) menggunakan Fuzzy Time Series Ruey Chyn Tsaur dalam meramalkan curah hujan di PPKS Sentang dengan perolehan hasil tingkat presisi akurasi metode sebesar 99,63\%. Julisman \& Erlin (2014) memprediksi tingkat curah hujan di Kota Pekanbaru menggunakan logika fuzzy mamdani dengan variabel bebas yang digunakan adalah suhu, tekanan, kecepatan angin dan kelembaban relatif. Rachmawati \& Anifah (2019) memprediksi curah hujan di Bandar Udara Juanda menggunakan metode Average Based dan High Order Fuzzy Time Series dengan perolehan hasil bahwa tingkat akurasi metode sebesar 96,06\%.

Selain metode FTS, algoritma Levenberg Marquardt (LM) dan Backpropagation digunakan oleh Ritha et al., (2016) dalam memprediksi curah hujan di Kota Tanjung Pinang 
dengan perolehan hasil bahwa tingkat akurasi algoritma LM lebih baik dibandingkan Backpropagation. Merdekawati \& Ismail (2018) menggunakan algoritma Levenberg Marquardt (LM) untuk memprediksi curah hujan di Jakarta dengan akurasi $96 \%$. Mukid \& Sugito (2011) memprediksi curah hujan di Kabupaten Purwodadi menggunakan regresi proses Gaussian dengan variabel bebas suhu dan kelembaban udara dengan perolehan hasil kuadrat eksponensial ARD memberikan peramalan terbaik dibandingkan kuadrat eksponensial isotopric, linear ARD, dan linear one. Rachmawati (2015) memprediksi curah hujan di Kota Pontianak menggunakan Jaringan Saraf Tiruan (JST) dengan perolehan hasil nilai akurasi data bulanan sebesar $100 \%$, sedangkan skala harian sebesar $52 \%$. Dewi et al., (2021) memprediksi curah hujan di Lombok menggunakan JST Backpropagation dengan variabel bebas adalah data suhu, kelembaban udara dan tekanan udara dengan perolehan hasil kurang akurat. Hal ini diakibatkan bobot dan parameter jaringan yang digunakan belum optimal. Seprima \& Defrianto (2020) memprediksi curah hujan dan kelembaban udara Kota Pekanbaru menggunakan Monte Carlo berprinsip pada fungsi deret fourier dengan hasil eror sebesar 0,0887913.

Prediksi curah hujan melalui return level menggunakan pendekatan distribusi GEV dilakukan oleh Rusgiyono et al. (2015) di Kota Semarang. Nara (2017) di Pulau Ambon, Ginting \& Putuhena (2017), (Rinaldi, 2016) dan Adiyani (2019) di Pulau Jawa. Djuraidah et al., (2019) melakukan peramalan curah hujan ekstrim di Provinsi Banten menggunakan Copula Gaussian dengan tingkat akurasi $80 \%$. Prediksi Curah hujan menggunakan machine learning dilakukan oleh Sumi et al. (2012) dan (Hong, 2008), sedangkan Yang et al., (2007) menggunakan data mining.

Dalam penelitian ini, prediksi curah hujan DKI Jakarta menggunakan metode FTS dikarenakan pada kemampuan model dalam menangani data deret waktu tanpa perlu memvalidasi teori apapun (Selim \& Elanany, 2013). Metode FTS pertama kali digunakan oleh Song \& Chissom (1993) dalam memprediksi pendaftaran mahasiswa di Universitas Alabama menggunakan model komposisi max-min yang memiliki proses perhitungan rumit. Perbaikan akurasi model dilakukan oleh Tanuwijaya \& Chen (2009) dengan mengelompokkan relasi fuzzy berdasarkan antecedennya. Sah \& Konstantin Y, (2005) memodifikasi model Song \& Chissom (1993) dan Tanuwijaya \& Chen (2009) menggunakan metode waktu invariant dan menyelidiki pengaruh perubahan jumlah himpunan fuzzy. Perbaikan akurasi FTS terus dilakukan dengan berbagai cara, yakni dengan memperbaiki selang interval interval, fuzzy logical relationships, dan defuzzifikasi.

\section{METODE}

Data yang digunakan dalam penelitian ini adalah data curah hujan stasiun pengamatan Kemayoran pada Periode Januari 2018 s.d 2020 yang berasal dari Badan Pusat Statistik (BPS) DKI Jakarta. Jenis penelitian adalah penelitian kuantitatif dengan menggunakan metode prediksi curah hujan menggunakan FTS yang dikembangkan oleh Stevenson \& Porter (2009). Adapun langkahnya sebagai berikut:

1. Memasukkan data curah hujan di stasiun pengamatan Kemayoran pada periode 2018 s.d 2020.

2. Mendefinisikan himpunan semesta $U=\left[D_{\min }, D_{\max }\right]$ dimana $D_{\min }$ dan $D_{\max }$ adalah laju pertumbuhan curah hujan, kemudian membaginya menjadi interval $A_{1}, A_{2}, \ldots, A_{n}$ dengan panjang yang sama di mana jumlah kelas dihitung menggunakan aturan struggest, selanjutnya menghitung frekuensi dari masing-masing selang interval.

3. Mendefinisikan masing-masing himpunan fuzzy sesuai dengan hasil yang diperoleh pada langkah 1.

4. Melakukan defuzzyfikasi data menggunakan rumus pendekatan pada persamaan (1) 


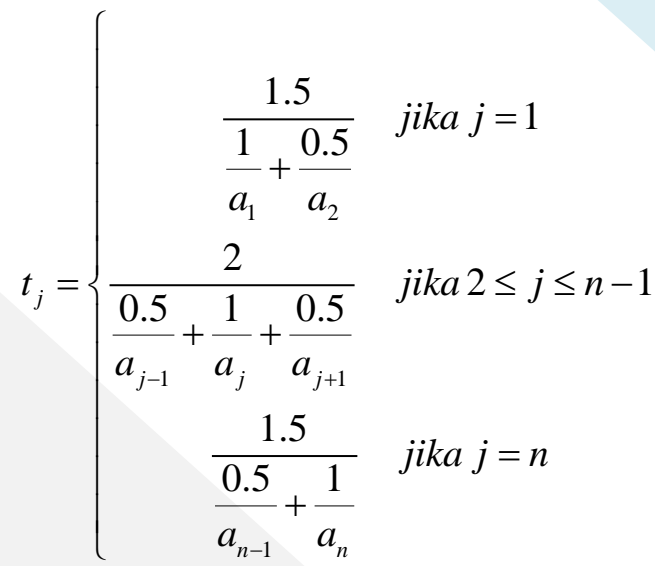

(1)

Di mana variabel persamaan (1) dijelaskan sebagai berikut: $a_{j-1}, a_{j}, a_{j+1}$ adalah titik tengah pada interval fuzzy $F_{j-1}, F_{j}, F_{j+1}$ dan $t_{j}$ adalah hasil prediksi dari perubahan persentase data di mana perubahan persentase peramalan tahun sebelumnya dapat digunakan untuk menentukan persentase tahun berikutnya.

5. Mengkonversi persentase hasil peramalan dalam bentuk angka, dengan menggunakan rumus:

$R_{t}^{*}=\left(t_{j} \times R_{t-1}\right)+$

$R_{t-1}$

(2)

Keterangan pada persamaan (2) yakni, $R_{t}^{*}$ adalah nilai proyeksi tingkat suku bunga tahun ke$t, t_{j}$ adalah laju defuzzifikasi, dan $R_{t-1}$ adalah data real tingkat suku bunga pada tahun sebelumnya.

6. Menghitung Average Forecasting Error Rate (AFER) menggunakan rumus:

$A F E R=\frac{\sum_{i=1}^{n} \frac{\left|A_{i}-F_{i}\right|}{A_{i}}}{n} \times$

$100 \%$

(3)

Keterangan:

$A_{i}$ adalah data curah hujan riil

$F_{i}$ adalah data proyeksi curah hujan

$n$ adalah banyaknya data

\section{HASIL DAN PEMBAHASAN}

\section{Hasil}

Data curah hujan merupakan data deret waktu yang didefinisikan sebagai kumpulan curah hujan yang diukur pada interval waktu sama secara berurut. Adapun data curah hujan di Stasiun Kemayoran pada periode 2018 s.d 2020 disajikan pada Tabel 1.

Tabel 1. Data Curah Hujan di Stasiun Kemayoran (mm)

\begin{tabular}{llll}
\hline Bulan & 2018 & 2019 & 2020 \\
\hline Januari & 215,1 & 383,9 & 618,0 \\
Februari & 431,2 & 270,1 & 1043,2 \\
Maret & 188,6 & 327,3 & 220,7 \\
April & 159,1 & 194,6 & 182,8 \\
Mei & 16,7 & 47,8 & 50,4
\end{tabular}




\begin{tabular}{llll} 
Juni & 12,6 & 23,1 & 21,1 \\
Juli & 14,5 & 0,0 & 12,1 \\
Agustus & 33,0 & 0,0 & 10,0 \\
September & 62,0 & 1,0 & 151,9 \\
Oktober & 133,8 & 1,0 & 208,3 \\
November & 140,9 & 50,1 & 87,3 \\
Desember & 52,3 & 263,8 & 134,7 \\
\hline \multicolumn{4}{c}{ Sumber: BPS Provinsi DKI Jakarta }
\end{tabular}

Berdasarkan Tabel 1. Curah hujan tertinggi terjadi pada bulan Februari 2020 sebesar 1043,2 mm, sedangkan pada bulan Juli dan Agustus tahun 2019 tidak terjadi hujan. Adapun ratarata curah hujan sepanjang tahun 2018 s.d 2020 adalah 162,61 mm dengan simpangan baku sebesar $206 \mathrm{~mm}$.

Proyeksi curah hujan menggunakan FTS memiliki 5 langkah, adapun uraiannya adalah sebagai berikut:

Tabel 2. Laju Pertumbuhan Curah Hujan

\begin{tabular}{llllll}
\hline Bulan & $\begin{array}{l}\text { Curah } \\
\text { Hujan }(\%)\end{array}$ & Bulan & $\begin{array}{l}\text { Curah } \\
\text { Hujan (\%) }\end{array}$ & Bulan & $\begin{array}{l}\text { Curah } \\
\text { Hujan }(\%)\end{array}$ \\
\hline Jan - Feb 2018 & 100,46 & Jan - Feb 2019 & $-29,64$ & Jan - Feb 2020 & 68,80 \\
Feb - Mar 2018 & $-52,26$ & Feb - Mar 2019 & 21,18 & Feb - Mar 2020 & $-78,84$ \\
Mar - Apr 2018 & $-15,64$ & Mar- Apr 2019 & $-40,54$ & Mar - Apr 2020 & $-17,17$ \\
Apr - Mei 2018 & $-89,50$ & April - Mei 2019 & $-75,44$ & Apr - Mei 2020 & $-72,43$ \\
Mei - Juni 2018 & $-24,55$ & Mei - Juni 2019 & $-51,67$ & Mei - Juni 2020 & $-58,13$ \\
Juni - Juli 2018 & 15,08 & Juni - Juli 2019 & $-100,00$ & Juni - Juli 2020 & $-42,65$ \\
Juli - Agus 2018 & 127,59 & Juli - Agus 2019 & 0,00 & Juli - Agus 2020 & 734,71 \\
Agus - Sept 2018 & 87,88 & Agus - Sept2019 & 0,00 & Agus - Sept2020 & 50,40 \\
Sept - Okt 2018 & 115,81 & Sept - Okt 2019 & 0,00 & Sept - Okt 2020 & 37,13 \\
Okt - Nov 2018 & 5,31 & Okt - Nov 2019 & 4910,00 & Okt - Nov 2020 & $-58,09$ \\
Nov - Des 2018 & $-62,88$ & Nov - Des 2019 & 426,55 & Nov - Des 2020 & 54,30 \\
Des 2018 - Jan 2019 & 634,03 & Des 2019 - Jan 2020 & 134,27 & & \\
\hline
\end{tabular}

Olah data pada Tabel 2. Menunjukkan bahwa laju pertumbuhan cuaca tertinggi terjadi pada November 2019, sedangkan terendah pada Mei 2018. Langkah selanjutnya adalah penentuan jumlah interval kelas menggunakan aturan sturgess. Adapun hasil yang diperoleh disajikan pada Tabel 3.

Tabel 3. Interval Fuzzy dan Nilai Linguistik Berdasarkan Distribusi Perubahan Persentase Curah Hujan

\begin{tabular}{|c|c|c|c|c|c|}
\hline No. & Interval & Batas Kiri & $\begin{array}{l}\text { Nilai } \\
\text { Tengah }\end{array}$ & $\begin{array}{l}\text { Batas } \\
\text { Kanan } \\
\end{array}$ & $\begin{array}{l}\text { Nilai } \\
\text { Linguistik }\end{array}$ \\
\hline 1 & $A_{1}$ & $-89,5$ & 318 & 725,5 & $a_{1}$ \\
\hline 2 & $A_{2}$ & 725,5 & 1133 & 1540,5 & $a_{2}$ \\
\hline 3 & $A_{3}$ & 1540,5 & 1948 & 2355,5 & $a_{3}$ \\
\hline 4 & $A_{4}$ & 2355,5 & 2763 & 3170,5 & $a_{4}$ \\
\hline 5 & $A_{5}$ & 3170,5 & 3578 & 3985,5 & $a_{5}$ \\
\hline 6 & $A_{6}$ & 3985,5 & 4393 & 4800,5 & $a_{6}$ \\
\hline 7 & $A_{7}$ & 4800,5 & 5208 & 5615,5 & $a_{7}$ \\
\hline
\end{tabular}

Langkah selanjutnya adalah menentukan Fuzzy Logic Relationship (FLRG) yang terbentuk dari left-hand side (LHS) dan right hand side (RHS) yang sudah ditentukan pada Tabel 3. Adapun FLRG disajikan pada Tabel 4.

Tabel 4. Distribusi FLRG

\begin{tabular}{cl}
\hline Distribusi FLRG & Frekuensi \\
\hline$A_{1} \rightarrow A_{1}$ & 31 \\
$A_{1} \rightarrow A_{2}$ & 1 \\
$A_{1} \rightarrow A_{7}$ & 1 \\
$A_{7} \rightarrow A_{1}$ & 1 \\
$A_{2} \rightarrow A_{1}$ & 1 \\
\hline
\end{tabular}


Berdasarkan Tabel 4. Maka aturan fuzzy yang akan digunakan adalah $A_{1} \rightarrow A_{1}, A_{7} \rightarrow$ $A_{1}, A_{2} \rightarrow A_{1}$. Dengan menggunakan laju defuzzifikasi untuk data curah hujan pada persamaan (1), diperoleh laju yang disajikan pada Tabel 5 .

\begin{tabular}{|c|c|c|}
\hline No. & Interval & $\begin{array}{l}\text { Laju } \\
\text { Defuzzifikasi }\end{array}$ \\
\hline 1 & $A_{1}$ & 372,4611 \\
\hline 2 & $A_{2}$ & 737,5684 \\
\hline 3 & $A_{3}$ & 1761,159 \\
\hline 4 & $A_{4}$ & 2637,333 \\
\hline 5 & $A_{5}$ & 3482,707 \\
\hline 6 & $A_{6}$ & 4316,076 \\
\hline 7 & $A_{7}$ & 4904,69 \\
\hline
\end{tabular}

Laju Defuzzyfikasi pada Tabel 5 akan dipergunakan dalam perhitungan proyeksi tingkat suku bunga menggunakan persamaan (2). Hasil proyeksi curah hujan disajikan pada Tabel 6.

Tabel 6. Hasil Proyeksi Curah Hujan

\begin{tabular}{|c|c|c|c|c|c|c|}
\hline Bulan & $\begin{array}{ll}\text { Data } & \text { Riil } \\
2018 & \\
\end{array}$ & $\begin{array}{l}\text { Data } \\
2018\end{array}$ & $\begin{array}{ll}\text { Data } & \text { Riil } \\
2019 & \end{array}$ & $\begin{array}{l}\text { Data } \\
2019\end{array}$ & $\begin{array}{l}\text { Data } \\
2020\end{array}$ & Proyeksi \\
\hline Januari & 215,1 & - & 383,9 & 271,07 & 618 & 1367,27 \\
\hline Pebruari & 431,2 & 1114,86 & 270,1 & 1989,75 & 1043,2 & 3203,08 \\
\hline Maret & 188,6 & 2234,90 & 327,3 & 1399,92 & 220,7 & 5406,88 \\
\hline April & 159,1 & 977,51 & 194,6 & 1696,39 & 182,8 & 1143,88 \\
\hline Mei & 16,7 & 824,61 & 47,8 & 1008,61 & 50,4 & 947,45 \\
\hline Juni & 12,6 & 86,56 & 23,1 & 247,75 & 21,1 & 261,22 \\
\hline Juli & 14,5 & 65,31 & 0 & 119,73 & 12,1 & 109,36 \\
\hline Agustus & 33 & 75,15 & 0 & 0,00 & 10 & 62,71 \\
\hline September & 62 & 171,04 & 1 & 0,00 & 151,9 & 83,76 \\
\hline Oktober & 133,8 & 321,34 & 1 & 5,18 & 208,3 & 787,29 \\
\hline Nopember & 140,9 & 693,48 & 50,1 & 5,18 & 87,3 & 1079,61 \\
\hline Desember & 52,3 & 730,28 & 263,8 & 2507,35 & 134,7 & 452,47 \\
\hline
\end{tabular}

\section{Pembahasan}

Hasil perhitungan curah hujan menggunakan FTS tidak menghasilkan akurasi yang baik, dengan nilai AFER sebesar 714,85 \%. Hal ini berbeda dengan hasil penelitian Desmonda \& Irwansyah (2018), Rahmawati et al., (2021), Julisman \& Erlin (2014), dan Rachmawati \& Anifah (2019) yang menyatakan bahwa FTS dapat dengan baik meramalkan curah hujan. Hasil AFER yang tinggi diperoleh karena rentang nilai dari curah hujan pada periode 2018 s.d 2020 sangat besar dan panjang kelas pada Tabel 3. Terlalu lebar sehingga tingkat eror yang dihasilkan tinggi, untuk itu perlu dilakukan perbaikan dalam penentuan panjang kelas interval dalam penelitian selanjutnya.

\section{PENUTUP}

Berdasarkan uraian pada hasil dan pembahasan diperoleh bahwa prediksi curah hujan di DKI Jakarta menggunakan percentage Fuzzy Time Series tidak menghasilkan akurasi yang baik hal ini dikarenakan nilai AFER yang tinggi. Selisih tertinggi antara data riil dan proyeksi terjadi pada Maret 2020 yakni sebesar 3203,08. Penyimpangan yang terjadi diakibatkan terlalu lebarnya rentang interval yang digunakan, untuk itu perlu dilakukan perbaikan selang interval. Selain itu pula dapat menggunakan metode FTS Ruey Chyn Tsaur. 


\section{DAFTAR PUSTAKA}

Adiyani, L. (2019). Nilai Faktor Pertumbuhan untuk Estimasi Hujan Rencana di Pulau Jawa. Jurnal Sumber Daya Air, 15(1), 56-68. https://doi.org/10.32679/jsda.v15i1.496

Desmonda, D., \& Irwansyah, M. A. (2018). Prediksi Besaran Curah Hujan Menggunakan Metode Fuzzy Time Series. 6(4), 141-145.

Dewi, K. N. A., Bhari, S., \& Irwansyah. (2021). Model prediksi curah hujan harian menggunakan jaringan syaraf tiruan backpropagation. Indonesian Physical Review, 2(1)(January 2019), 9-17. https://doi.org/10.29303/ipr.v2i1.17

Djuraidah, A., Suheni, C., \& Nabila, B. (2019). Peramalan curah hujan ekstrim di provinsi banten dengan model ekstrim spasial. Media Statistika, 12(1), 50-62. https://doi.org/10.14710/medstat.12.1.50-62

Eldi. (2020). Analisis Penyebab Banjir di DKI Jakarta. Jurnal Inovasi Penelitian, 1(6), 10571064.

Ginting, S., \& Putuhena, W. M. (2017). Hujan rancangan berdasarkan analisis frekuensi regional dengan metode tl-moment. Jurnal Sumber Daya Air, 12(1), 1-16. https://doi.org/10.32679/jsda.v12i1.160

Hong, W. (2008). Rainfall forecasting by technological machine learning models. Science Directed, 200, 41-57. https://doi.org/10.1016/j.amc.2007.10.046

Julisman, Z., \& Erlin. (n.d.). Prediksi Tingkat Curah Hujan di Kota Pekanbaru menggunakan Logika Fuzzy Mamdani.

Merdekawati, G. I., \& Ismail. (2018). Prediksi Curah Hujan di Jakarta Berbasis Algoritma Levenberg Marquardt. 24(100), 116-128.

Mukid, M. A., \& Sugito. (2011). Model Prediksi Hujan dengan Pendekatan Regresi Proses Gaussian. 113-122.

Nara, O. D. (2017). Distribusi Data Ekstrim Pada Daerah Aliran Sungai Rain Teaching Trend Analysis of Extrim Data Distribution on River Flow Area. 17(1), 1-8.

Nugroho, S. P. (2002). Evaluasi dan analisis curah hujan sebagai faktor penyebab bencana banjir jakarta (in Bahasa). Jurnal Sains \& Teknologi Modifikasi Cuaca, 3(2), 91-97.

Rachmawati, A. (2015). Prediksi Curah Hujan di Kota Pontianak Menggunakan Parameter Cuaca Sebagai Prediktor Pada Skala Bulanan, Dasarian dan Harian. Positron, V(2), 50-57.

Rachmawati, M. D., \& Anifah, L. (2019). Prediksi Curah Hujan Menggunakan Metode Average Based dan High Order Fuzzy Time Series di Bandar Udara Juanda. 03, 11-15.

Rahmawati, R., Sari, D. E., \& Rahma, A. N. (2021). Peramalan Curah Hujan di PPKS Bukit Sentang Dengan Menggunakan Fuzzy Time Series Ruey Chyn Tsaur. 17(1), 51-61. https://doi.org/10.24198/jmi.v17.n1.32820.51-61

Rinaldi, A. (2016). Sebaran Generalized Extreme Value (GEV) Dan Generalized Pareto (GP) untuk Pendugaan Curah Hujan Ekstrim di Wilayah DKI Jakarta. Al-Jabar: Jurnal Pendidikan Matematika, 7(1), 75-84. https://doi.org/10.24042/ajpm.v7i1.137

Ritha, N., Bettiza, M., \& Dufan, A. (2016). Prediksi Curah Hujan dengan Menggunakan Algoritma Levenberg- Marquardt dan Backpropagation. 5(2).

Rusgiyono, A., Wuryandari, T., \& Rahmawati, A. (2015). Model Curah Hujan Ekstrem Di Kota Semarang Menggunakan Estimasi Moment Probabilitas Terboboti. Media Statistika, 8(1), 13-22. https://doi.org/10.14710/medstat.8.1.13-22

Sah, M., \& Konstantin Y, D. (2005). Forecasting Enrollment Model Based on First-Order Fuzzy Time Series. Engineering and Technology, 1(1), 375-378. http://eprints.ecs.soton.ac.uk/15211/

Selim, K. S., \& Elanany, G. A. (2013). A new method for short multivariate fuzzy time series based on genetic algorithm and fuzzy clustering. Advances in Fuzzy Systems, 2013. https://doi.org/10.1155/2013/494239

Seprima, M., \& Defrianto. (2020). Prediksi Curah Hujan dan Kelembaban Udara Kota Pekan Baru Menggunakan Metode Monte Carlo. Komunikasi Fisika Indonesia, 17(3), 134-138. https://doi.org/10.31258/jkfi.17.3.134-138

Song, Q., \& Chissom, B. S. (1993). Forecasting enrollments with fuzzy time series - Part I. Fuzzy 
Sets and Systems, 54(1), 1-9. https://doi.org/10.1016/0165-0114(93)90355-L

Stevenson, M., \& Porter, J. E. (2009). Fuzzy Time Series Forecasting Using Percentage Change as the Universe of Discourse. 3(7), 464-467.

Sumi, S. M., Zaman, F., Mobile, A., Limited, S., \& Hirose, H. (2012). A rainfall forecasting method using machine learning models and its application to the Fukuoka city case. Amcs, December, 1-13. https://doi.org/10.2478/v10006-012-0062-1

Syaifullah, M. D. (2013). Kondisi Curah Hujan pada Kejadian Banjir Jakarta dan Analisis Kondisi Udara atas Wilayah Jakarta Bulan Januari - Februari 2013. 13.

Tanuwijaya, K., \& Chen, S. M. (2009). A new method to forecast enrollments using fuzzy time series and clustering techniques. Proceedings of the 2009 International Conference on Machine Learning and Cybernetics, 5(1), 3026-3029. https://doi.org/10.1109/ICMLC.2009.5212604

Yang, Y., Lin, H., Guo, Z., \& Jiang, J. (2007). A data mining approach for heavy rainfall forecasting based on satellite image sequence analysis \$. 33, 20-30. https://doi.org/10.1016/j.cageo.2006.05.010 